\title{
A Concepção de Estudantes de Fisioterapia que Participam do Ensino Baseado em Problemas sobre o Processo Saúde-Doença
}

\author{
Views on the Health-Disease Process Among \\ Physiotherapy Students to Have Participated in \\ Problem-Based Learning
}

\section{PALAVRAS-CHAVE \\ - Processo Saúde-Doença; \\ - Ensino Baseado em Problemas; \\ - Educação Médica; \\ - Fisioterapia.}

\section{KEYWORDS}

- Health-Disease Process;

- Problem-Based Learning;

- Medical Education;

- Physiotherapy.
Fabiola Chesani Hermes ${ }^{I}$ Luiz Roberto Agea CutoloI Sylvia Regina Pedrosa Maestrelli ${ }^{I}$

\section{RESUMO}

O objetivo deste ensaio foi investigar a concepção dos docentes e discentes fisioterapeutas que participam do Ensino Baseado em Problemas (PBL) sobre o processo saúde-doença. Trata-se de um estudo de natureza qualitativa, por meio do estudo de caso numa escola de ensino superior de Fisioterapia em Portugal. A técnica de coleta de dados foi o questionário. Os dados coletados foram analisados pela Análise de Conteúdo. Os resultados mostraram as categorias saúde como ausência de doença, saúde como bem-estar, saúde relacionada aos determinantes sociais e a percepção do sujeito. É possível no PBL uma prática pedagógica em prol de uma formação mais humana e crítica, desde que seja vivenciado enquanto método ativo de ensino nos moldes apontados na literatura.

\section{ABSTRACT}

The objective of the study was to investigate views on the health-disease process among physiotherapy teachers and students participating in PBL. This study was qualitative, taking its case study as a higher education school of Physical Therapy in Portugal. Data collection was performed by means of questionnaires, with the collected data analyzed via content analysis. PBL facilitates the possibility of pedagogical practices in favor of more humane and critical training, as long as it is experienced as the active method of teaching described in the literature. 


\section{INTRODUÇÃO}

Este ensaio faz parte da tese intitulada Limites e Possibilidades do Problem-Based Learning (PBL) na formação do fisioterapeuta. A tese foi defendida no Programa de Pós-Graduação em Educação Científica e Tecnológica da Universidade Federal de Santa Catarina (SC) em junho de 2014. As instituições que financiaram a pesquisa foram a Coordenação de Aperfeiçoamento de Pessoal de Nível Superior (Capes), com o número 8.794-11-1, e o Fundo de Apoio à Manutenção e ao Desenvolvimento da Educação Superior (Fumdes), com o número 2.279.

As transformações dos processos de ensino na ordem paradigmática e estrutural propõem novos métodos de ensino, centrados na aprendizagem do aluno, nova concepção do trabalho docente para promover a aprendizagem significativa, habilidades de pensamento crítico e reflexivo, e aprender a aprender mediante a revisão do exercício profissional ${ }^{1}$.

No contexto da saúde, os métodos de ensino apoiados na aprendizagem por descoberta e significância e que, em sintonia com o discurso corrente entre os educadores e reformadores do ensino superior, se propõem problematizadores são a Metodologia da Problematização com o Arco de Maguerez e a Aprendizagem Baseada em Problemas ou Problem Based Learning $(P B L)^{2}$.

A Metodologia da Problematização com o Arco de Maguerez nos cursos da área da saúde tem como principal referencial os trabalhos de Neusi Berbel ${ }^{3,4,5}$, iniciados na década de 1990. Berbel cita o Método do Arco, de Charles Maguerez, como um dos primeiros referenciais teóricos que auxiliaram na fundamentação do que a autora iria desenvolver e denominar Metodologia da Problematização com o Arco de Maguerez.

O PBL foi implantado como estratégia de ensino no final da década de 1960, na Universidade de McMaster, no Canadá, e na Universidade de Maastricht, na Holanda, pouco depois. Desde então, várias universidades ao redor do mundo têm adotado essa metodologia, inicialmente nos cursos da área da saúde, mas também na formação de áreas diversificadas, como os cursos de Engenharias, Economia, Psicologia, Arquitetura, Física, Química e Biologia, entre outros.

Os novos enfoques pedagógicos são bem-vindos, mas o que se deve considerar, agora, não é o método em si, mas quais as possibilidades do método para se entender saúde-doença dentro de sua complexidade dialética e promover a formação de profissionais voltados para o sistema de sáude vigente, o modelo integral em saúde ${ }^{6}$.

Há uma escassez de dados fundamentados sobre o padrão de desempenho dos graduandos em Medicina no Brasil, ainda que a maioria dos trabalhos nacionais e internacionais, alguns citados acima, tenha como foco as habilidades cognitivas $^{7}$. Alguns autores ${ }^{8,9,10}$ relataram atitudes relacionadas com um modelo integral em saúde e que, na ótica dos graduados, o curso proporcionou uma formação humanista, que existem ganhos maiores com relação à saúde pública por parte de estudantes vinculados ao método de $P B L$ e que estudantes de currículo PBL tinham 3,1 vezes mais interesse em Atenção Primária à saúde que os demais.

Identificamos que, na Medicina, poucas pesquisas relacionam o $P B L$ com um modelo integral de saúde. Se na Medicina, área em que o $P B L$ é amplamente difundido, existe esta escassez, na Fisioterapia a escassez de estudos sobre o PBL na formação profissional é muito maior. Diante desta situação, o objetivo desta pesquisa foi investigar a concepção dos docentes e discentes fisioterapeutas que participam do $P B L$ sobre o processo saúde-doença.

\section{MÉTODO}

Nesta pesquisa, quanto à natureza das variáveis pesquisadas, optou-se por uma abordagem qualitativa por meio do estudo de caso. O estudo de caso ocorreu num curso de Fisioterapia de Portugal de abril a junho de 2012. Esta escola foi eleita para realizar o estudo de caso porque no Brasil os cursos de Fisioterapia adotam o modelo misto do $P B L$, e o modelo adotado na escola de Fisioterapia é o integral. No modelo misto, algumas unidades curriculares utilizam o PBL, enquanto outras mantêm o formato tradicional, ao passo que no modelo integrado todo o currículo é organizado em torno de problemas ${ }^{11}$.

Os participantes da pesquisa foram os alunos do curso de Fisioterapia do primeiro ao quarto ano. A coleta de dados se iniciou somente após a aprovação do Comitê de Ética e Pesquisa, com o número 0525/2012, e o aceite e a assinatura no Termo de Consentimento Livre e Esclarecido. Os critérios de inclusão neste estudo foram: os alunos que assinassem o Termo de Consentimento e aqueles que estivessem regularmente matriculados no curso de Fisioterapia. Optou-se por uma amostragem não probabilística por conveniência, pois as amostras foram formadas por pessoas que estão ao alcance do pesquisador e dispostas a responder aos questionários e às entrevistas.

A técnica de coleta de dados utilizada foi o questionário. Para a coleta de dados, os participantes foram abordados pessoalmente no ambiente da universidade e no horário estabelecido por eles, isto é, face a face.

Uma primeira versão do questionário foi aplicada a uma amostra mais reduzida de respondentes. Graças a este procedimento, foi possível detectar alguns problemas na sua construção, sendo que os principais se referiam à passagem da língua portuguesa do Brasil para a língua portuguesa de 
Portugal. Estas falhas foram corrigidas após sua detecção, processo que originou uma versão reformulada do questionário.

O questionário definitivo aplicado aos alunos apresenta duas páginas devidamente identificadas e é constituído por dez questões abertas e três blocos de questões. $\mathrm{O}$ primeiro bloco versa sobre a saúde-doença; o segundo bloco questiona potencialidades, fragilidades, interdisciplinaridade, trabalho em equipe e avaliação das sessões tutoriais; e o terceiro bloco questiona sobre o currículo. Os questionários foram aplicados na universidade, no final da sessão tutorial, com a presença do pesquisador, e o tempo previsto de preenchimento foi de 20 minutos em cada turma. Do primeiro ano, foram preenchidos 35 questionários, do segundo ano 46, do terceiro ano 28, e do quarto ano 8 questionários. Ao todo, foram coletados 122 questionários do primeiro ao oitavo ano, mas cinco foram excluídos porque os alunos deixaram em branco ou a letra estava ilegível. Não foi possível aplicar mais questionários no oitavo período porque estes alunos estavam realizando estágio no ambiente hospitalar. Foram coletados ao todo 117 questionários preenchidos adequadamente. O curso de Fisioterapia tem uma média de 60 alunos matriculados por ano e tem quatro anos de duração. Portanto, tem 240 alunos matriculados, e a amostra do estudo foi de $48,75 \%$ da população.

Para fins de compreensão, os questionários foram divididos em quatro grupos de alunos, denominados neste estudo pela letra $Q$. Os números ordinais de $1^{\circ}$ a $4^{\circ}$ representam os anos do curso de Fisioterapia. Os números naturais que seguem as letras $(1,2,3)$ representam o número do questionário daquele grupo. Portanto, o questionário Q1ำ1 é o questionário do primeiro ano e número 1 .

Os dados coletados foram analisados de acordo com a Análise de Conteúdo e depois triangulados ${ }^{12}$. Neste estudo, optamos por análise do conteúdo latente, por ser dinâmica e social.

\section{RESULTADOS}

A estratégia para o tratamento dos dados dos questionários e das entrevistas envolveu a redução de dados, a apresentação dos mesmos e as conclusões. Quanto à redução dos dados, iniciou-se com a transcrição das entrevistas. Para manter o anonimato das entrevistas, foi estabelecido um roteiro de codificação, que associa os entrevistados a uma referência alfabética e numérica.

Os três blocos de questões desenvolvidos nos questionários e nas entrevistas foram denominados blocos temáticos. Os resultados foram apresentados em blocos temáticos a priori e em categorias a posteriori. Não houve separação entre uma técnica de coleta de dados e a outra técnica, pois o objetivo do estudo foi construir um panorama crítico sobre a concepção dos docentes e discentes fisioterapeutas que participam do $P B L$ sobre o processo saúde-doença, e não confrontar falas dos participantes, além do que as falas foram muito similares entre um grupo e outro, e entre uma técnica e outra, isto é, entre as entrevistas e os questionários.

No bloco temático concepção do processo saúde-doença, emergiram as categorias: saúde como ausência de doença, saúde como bem-estar, saúde relacionada aos determinantes sociais e percepção do sujeito. Os dados da relação do número de alunos com as categorias saúde como ausência de doença, saúde como bem-estar e saúde relacionada com os determinantes sociais em saúde (DSS) estão representados na Tabela 1.

\begin{tabular}{|c|c|c|c|}
\hline \multicolumn{4}{|c|}{$\begin{array}{l}\text { Relação do número de alunos com as categorias } \\
\text { saúde como ausência de doença, saúde como } \\
\text { bem-estar e saúde relacionada com os DSS }\end{array}$} \\
\hline $\begin{array}{l}\text { Ano do curso } \\
\text { de Fisioterapia }\end{array}$ & $\begin{array}{l}\text { Alunos que } \\
\text { entendem a } \\
\text { saúde como } \\
\text { ausência } \\
\text { de doença }\end{array}$ & $\begin{array}{c}\text { Alunos que } \\
\text { entendem a } \\
\text { saúde como } \\
\text { bem-estar }\end{array}$ & $\begin{array}{l}\text { Alunos que } \\
\text { entendem a } \\
\text { saúde como } \\
\text { determinantes } \\
\text { sociais }\end{array}$ \\
\hline $1^{\circ}$ ano -37 & $16(47 \%)$ & $12(35 \%)$ & $6(18 \%)$ \\
\hline $2^{\circ}$ ano -48 & $13(31 \%)$ & $27(64 \%)$ & $2(5 \%)$ \\
\hline $3^{\circ}$ ano -28 & $9(36 \%)$ & $15(60 \%)$ & $1(4 \%)$ \\
\hline $4^{\mathrm{o}}$ ano -8 & $5(62 \%)$ & $3(38 \%)$ & $0(0 \%)$ \\
\hline Total: 121 & $43(39,50 \%)$ & $57(52,50 \%)$ & $9(8 \%)$ \\
\hline
\end{tabular}

Nessa tabela, percebemos um predomínio na forma de pensar a saúde como ausência de doença e como bem-estar, isto é, 100 (92\%) participantes desta pesquisa pensam desta forma, um predomínio que acontece do primeiro ao quarto ano do curso de Fisioterapia.

Quando comparados com os alunos de outros anos, os do primeiro ano apresentam uma porcentagem maior da compreensão da saúde como ausência de doença, outros 35\% têm a ideia de bem-estar, ao passo que para seis participantes a ideia de saúde como DSS é bem clara. No segundo ano, a percepção da saúde como bem-estar é bem clara, e apenas dois (5\%) relacionam a saúde com os DSS. No terceiro ano, também identificamos o mesmo predomínio da compreensão como bem-estar, e apenas um (4\%) como DSS. Mesmo diante da amostra pequena do quarto ano, houve predomínio na percepção da saúde como ausência de doença, desconsiderando os DSS.

A preocupação com a saúde está melhorando lenta e progressivamente, é o que parece do terceiro ao primeiro ano. Entende-se que esta melhora esteja relacionada aos problemas encontrados na estruturação do modelo integral de $P B L$, visto que os alunos do quarto ano compõem a primeira turma do 
curso de Fisioterapia, formada pelo modelo de PBL integral. Já os alunos do primeiro ano vivenciaram algumas mudanças promovidas pela coordenação do curso e pelos tutores ao detectarem alguns problemas na adaptação ao método integral. Portanto, esta divergência na forma de ver e pensar a saúde pode ocorrer pela juventude do método integral no curso, e talvez os tutores estejam percebendo a necessidade de direcionar a saúde para os DSS.

Na percepção dos alunos sobre a saúde como ausência de doença, registrou-se que o modo de ver e pensar saúde ainda corresponde ao modelo biomédico e se distancia do reconhecimento do ser humano para além de um conjunto de órgãos e sistemas que apresenta lesões ou disfunções, as quais podem ser resolvidas com o auxílio de outros recursos diferentes dos tecnológicos. Este registro é representado pelas seguintes falas dos acadêmicos:

Saúde é o estado da pessoa, enquanto doença é um determinado problema que a pessoa tenha, quer psicológico, físico ou mental. (Q1ำ3)

A doença resulta de um desequilíbrio que acontece no nosso corpo. Saúde é um conceito mais abrangente que designa um bem-estar físico, psicológico e social. (Q2ª)

O processo saúde-doença entende como sendo a ausência de patologia seja saúde, e ter patologia seja doença. (Q32ㅡ)

No processo saúde-doença, o que eu entendi é que, para passar de um estado de saúde ao de doença, basta existir uma diferença ou alteração de um sistema, no qual o fisioterapeuta terá que atuar para voltar ao estado de saúde. (Q4ำ1)

Na categoria saúde como bem-estar, $52 \%$ dos alunos relacionam a saúde com este termo. Esta categoria é representada por algumas falas dos acadêmicos:

Saúde é o bom estado físico e mental. Doença é o estado de mal-estar, falta de bem-estar em nível físico ou mental ou social. (Q1ำ11)

Saúde é a capacidade de estar bem, sem qualquer complicação ou problema. Doença é quando o estar bem não se direciona. (Q2ํ)

Saúde é um bem-estar físico, emocional, psicológico e socioambiental. Doença significa que algum destes domínios está alterado. (Q3ㄴ22)
Saúde é o bem-estar emocional, físico e social, sendo que a doença se caracteriza por uma alteração nestes domínios. (Q4%)

Na categoria saúde relacionada aos determinantes sociais, os dados revelam que, dos 121 participantes da pesquisa, somente nove $(7,43 \%)$ relacionam a saúde com os determinantes sociais. Sobre esta categoria, alguns acadêmicos relataram:

Não é um conceito de uma pessoa não ter nenhuma doença seja saudável, e aqui no curso é muito isto, é o indivíduo como um todo, não só o físico e não o psicológico e o social, mas o contexto ambiental em que ela se insere. (Q1ํㅡㄹ)

Uma pessoa não ter nenhuma doença seja saudável e aqui no curso experimenta-se muito isto, é o individuo como um todo, não só o físico e não o psicológico e o social, o contexto ambiental em que ela se insere. Acho que é muito por aí. (Q2³)

Saúde engloba não só a patologia, mas todo o ambiente que envolve o indivíduo. (Q3ำ)

Na categoria percepção do sujeito, alguns alunos do primeiro ao quarto ano confundem o sujeito com a própria doença, aproximando-se da visão biológica e patológica, e se distanciando da visão de sujeito integral ou relacionada aos determinantes sociais em saúde.

Vejo o utente como uma pessoa na qual devo ter em conta uma série de considerações em termos físicos e psicológicos e alguém pelo qual devo fazer tudo o que estiver ao meu alcance para tentar resolver ou pelo menos melhorar a situação em que ele se encontra. (Q13)

No nosso caso, vemos a pessoa como paciente, como alguém que necessita de nossa ajuda, de nossos conhecimentos e de nosso apoio. $\left(\mathrm{Q}^{2} \stackrel{\circ}{ }\right)$

O utente é a pessoa que recorre a um técnico de saúde, solicitando a sua ajuda no combate à patologia/problema. (Q323)

Um utente é uma pessoa que recorre a um profissional de saúde porque apresenta algum problema de saúde. (Q4²)

\section{DISCUSSÃO}

Saúde como ausência de doença

Este modelo está aquém das necessidades de saúde das pessoas, pois cada indivíduo é singular e expressa essa singulari- 
dade de forma diferente: mora em determinada comunidade com ambiente específico, com sua família ou não, com certos hábitos e costumes, com sua raça, credo, profissão, forma de ser e de expressar suas angústias, tristezas, medos, alegrias, paixões, tensões, etc. Quando identificamos estas características, estamos percebendo as necessidades de saúde deste indivíduo. O profissional que não reconhece estas singularidades e percebe o sujeito como uma lesão em determinado órgão ou sistema deverá ampliar o seu olhar. A saúde é "a margem de tolerância às infidelidades do meio", e neste sentido implica poder adoecer e sair do estado patológico ${ }^{13}$. Em outras palavras, a saúde é entendida por referência à possibilidade de enfrentar situações novas. A doença não é apenas o desaparecimento de uma ordem fisiológica, mas o aparecimento de uma nova ordem vital. O patológico implica pathos, um sentimento direto e concreto de sofrimento e de impotência, sentimento de vida contrariada. A saúde, por sua vez, envolve muito mais do que a possibilidade de viver em conformidade com o meio externo, implica a capacidade de instituir novas normas.

A Tabela 1 deixa bem visível a forma inversa de ver a ausência de doença e bem-estar dos alunos que estão no segundo e terceiro ano e dos alunos do primeiro e quarto ano. E a evolução da compreensão dos DSS do primeiro ao quarto ano. Isto implica identificar não somente a causa biológica de uma pneumonia, por exemplo, ou as relações de causa e efeito, mas identificar como determinados grupos da população são mais susceptíveis do que outros a contrair certas patologias. É neste ponto que os DSS atuam de forma mais complexa. Portanto, os DSS incluem as condições mais gerais de uma sociedade - socioeconômicas, culturais e ambientais - e se relacionam com as condições de vida e trabalho de seus membros, como habitação, saneamento, ambiente de trabalho, serviços de saúde e educação, incluindo também a trama de redes sociais e comunitárias. A Organização Mundial da Saúde (OMS) define os DSS como as condições sociais em que as pessoas vivem e trabalham.

Os DSS surgiram no século XX, quando se percebeu que a epidemia comportamental e a teoria unicausal deixaram de resolver os problemas. Os dois principais aspectos desta revolução eram o foco na saúde ao invés de na doença e a preconização de uma perspectiva ecológica. Nesse contexto, emergiram os principais conceitos da segunda revolução da saúde: "promoção da saúde e estilo de vida".

Estes conceitos foram difundidos por Marc Lalonde, depois por Julius Richmond e pela OMS, na Declaração de Alma-Ata, em 1978. A reunião de Alma-Ata lançou as bases da estratégia de Atenção Primária da Saúde (APS), como chave para que a "Meta de Saúde para Todos" fosse alcançada. A
APS propunha uma série de estratégias, como a coordenação intersetorial, a participação social e a reestruturação dos sistemas de saúde, a partir dos serviços básicos, para lograr equidade no acesso e qualidade da atenção à saúde ${ }^{14}$.

Já, em 1982, foi lançada uma versão da APS que deixava de lado a ação sobre os DSS e expurgava seu conteúdo transformador dos sistemas de saúde para se concentrar apenas na aplicação de algumas medidas específicas, como reidratação oral e suplementação alimentar para populações carentes. Em 1986, novamente, os DSS reaparecem com a Carta de Ottawa, lançada durante a $1^{\underline{a}}$ Conferência Internacional sobre Promoção da Saúde, onde se reconhece que "as condições e os recursos fundamentais para a saúde são: paz, habitação, educação, alimentação, renda, ecossistema estável, recursos sustentáveis, justiça social e equidade" $(p .20)^{14}$.

A década seguinte, com o debate sobre as Metas do Milênio, novamente dá lugar a uma ênfase nos determinantes sociais, que se afirmam com a criação da Comissão Global sobre Determinantes Sociais da Saúde da OMS, em 2005. Esta Comissão foi anunciada com a intenção de fazer a agenda pró-equidade avançar e para aumentar o apoio da Organização dos Estados-Membros na implantação de abordagens abrangentes dos problemas de saúde, incluindo suas raízes sociais e ambientais. A equidade em saúde, então, passa a ser definida em relação à posição dos indivíduos na hierarquia social e, consequentemente, aos gradientes de poder social, econômico e político acumulados.

Para combater as iniquidades em saúde, temos que conhecer as condições econômicas, culturais e o ambiente geral da população. Também devem ser estabelecidas relações entre as condições de vida e trabalho e os determinantes mais específicos e o estilo de vida do indivíduo. Estes fatores não devem ser vistos isoladamente, mas devem se inter-relacionar.

Segundo o relatório final da Comissão dos DSS, as recomendações gerais da Comissão são: melhorar as condições de vida cotidianas, isto é, as circunstâncias em que as pessoas nascem, crescem, vivem, trabalham e envelhecem; abordar a distribuição desigual de poder, dinheiro e recursos; quantificar e compreender o problema e avaliar o impacto da ação, isto é, alargar a base de conhecimento, desenvolver um corpo de recursos humanos formado sobre os determinantes sociais da saúde e promover a consciência pública sobre o tema ${ }^{15}$.

Um estudo analisou as concepções de dois docentes gestores, 12 docentes tutores e 12 estudantes da primeira série do curso de Medicina sobre o PBL no currículo da Faculdade de Medicina de Marília (Famema), em 2002, e sua relação com a formação médica. A análise dos dados desse estudo permitiu considerar que: o processo educacional realizado na Fame- 
ma tem sido construído coletivamente, o contexto de ensino-aprendizagem e da prática profissional é dinâmico e repleto de contradições e opiniões diferentes, e a educação permanente para os docentes é um recurso necessário, que precisa ser estendido à prática profissional dos profissionais de saúde. Ainda nas falas de docentes e estudantes, identificou-se que a saúde da pessoa não envolve só o bem-estar físico e que o médico, para cuidar de uma pessoa, precisa conhecê-la e ao seu contexto de vida, porque os conhecimentos só sobre o biológico ou sobre os tratamentos medicamentosos e/ou cirúrgicos não são suficientes ${ }^{16}$

\section{Saúde como bem-estar}

O termo bem-estar está relacionado com o momento após a Segunda Guerra Mundial, em 1946, quando a OMS apresentou o seguinte conceito de saúde: "Saúde é o estado de completo bem-estar físico, mental e social, e não meramente a ausência de doença ou incapacidade" (p.10) ${ }^{18}$. Como o momento histórico atual é outro, este termo não contempla mais as necessidades de saúde da população e as exigências da política pública em saúde mundial e atual. Mas, na época, esta definição foi um avanço para a saúde, pois tinha uma visão mais ampla e positiva da saúde, que incluiria fatores como alimentação, atividade física e acesso aos sistemas de saúde.

Atualmente, a compreensão de saúde vai muito além desse conceito. Quando se fala em saúde como um estado completo, quer dizer, saúde na sua totalidade, esta expressão é de caráter utópico e inalcançável, pois quem tem completo bem-estar físico e mental? Por exemplo, quem usa óculos de grau não tem completo estado físico, e isto não quer dizer que seja uma pessoa doente; na realidade, ela tem saúde e enfrenta uma alteração em seu sistema ocular. Além disso, o termo bem-estar indica um estado engessado do processo saúde-doença, pois o indivíduo não permanece constantemente em estado de bem-estar. Uma pessoa, na sua existência, não vive sem angústias ou conflitos, e estas sensações são inerentes à própria história de cada ser humano e de cada sociedade ${ }^{13}$. As infidelidades do meio, os fracassos, os erros e o mal-estar são parte constitutiva de nossa história, e, desde o momento em que nosso mundo é um mundo de acidentes possíveis, a saúde não poderá ser pensada como carência de erros, mas, sim, como a capacidade de enfrentá-los.

Portanto, da forma como se apresenta, este conceito é inatingível e não pode ser usado como meta pelos serviços de saúde atuais e nem como preceito dos profissionais de saúde, em constante formação. Atualmente, o conceito ampliado de saúde é o que contempla as necessidades e exigências da população e do sistema de saúde. O conceito ampliado para a saúde é a resultante das condições de alimentação, habitação, educação, renda, meio ambiente, trabalho, transporte, emprego, lazer, liberdade, acesso e posse da terra e acesso aos serviços de saúde.

\section{Saúde relacionada aos determinantes sociais}

Os determinantes sociais da saúde surgiram no século $X X$, quando se percebeu que a epidemia comportamental e a teoria unicausal deixaram de resolver os problemas. Nesse contexto, emergiram os principais conceitos da segunda revolução da saúde, "promoção da saúde e estilo de vida". Os determinantes reaparecem com a Carta de Ottawa, lançada durante a $1^{\underline{a}}$ Conferência Internacional sobre Promoção da Saúde.

O modelo de Dahlgren e Whitehead destaca-se na compreensão dos DSS. Este modelo inclui os DSS dispostos em diferentes camadas, desde uma camada mais próxima dos determinantes individuais até uma camada distal, onde se situam os macrodeterminantes. Neste modelo, os indivíduos estão na base, com características individuais de idade, sexo e fatores genéticos que, evidentemente, exercem influência sobre seu potencial e suas condições de saúde. Na camada imediatamente externa, aparecem o comportamento e os estilos de vida individuais. Esta camada está situada no limiar entre os fatores individuais e os DSS, já que os comportamentos, muitas vezes entendidos apenas como de responsabilidade individual, dependentes de opções feitas pelo livre-arbítrio, na realidade podem também ser considerados parte dos DSS, já que essas opções estão fortemente condicionadas por determinantes sociais - como informações, propaganda, pressão dos pares, possibilidades de acesso a alimentos saudáveis e espaços de lazer, etc. A camada seguinte destaca a influência das redes comunitárias e de apoio, cuja maior ou menor riqueza expressa o nível de coesão social que, como vimos, é de fundamental importância para a saúde da sociedade como um todo. No próximo nível estão representados os fatores relacionados a condições de vida e de trabalho, disponibilidade de alimentos e acesso a ambientes e serviços essenciais, como saúde e educação, indicando que as pessoas em desvantagem social correm um risco diferenciado, criado por condições habitacionais mais humildes, exposição a condições mais perigosas ou estressantes de trabalho e acesso menor aos serviços. Finalmente, no último nível estão situados os macrodeterminantes relacionados às condições econômicas, culturais e ambientais da sociedade e que possuem grande influência sobre as demais camadas.

Nesta pesquisa, verifica-se pouca inserção dos alunos do curso de Fisioterapia com a percepção de saúde com os determinantes de saúde. A percepção predominante dos alunos do 
primeiro ao quarto ano ainda é a da saúde relacionada com a doença e com o bem-estar. Na formação do fisioterapeuta, devem-se desenvolver recursos humanos conscientes sobre os determinantes sociais da saúde, tanto no Brasil quanto em Portugal, de forma emergencial.

\section{Percepção do sujeito}

Alguns alunos do primeiro ao quarto ano confundem o sujeito com a própria doença, aproximando-se da visão biológica e patológica e distanciando-se da visão de sujeito integral ou relacionada aos determinantes sociais em saúde.

Acreditamos que esta percepção do sujeito esteja articulada à forma de o aluno perceber o processo saúde-doença como ausência de doença e como bem-estar. Se percebem a saúde como ausência de doença e bem-estar, os alunos não conseguem ver o paciente como sujeito, eles veem o paciente como a doença, e a tendência deste profissional é focar a reabilitação.

Consideramos compreensível que os alunos entendam o sujeito como a própria doença, pois, para eles, o conceito de saúde está enraizado no modelo biomédico. As mudanças são urgentes na área da saúde, pois, enquanto não houver a apreensão do conceito atualizado em saúde, será difícil separar o sujeito da própria doença e começar a compreendê-lo com os DSS. Acreditamos que o passo inicial seja o "saber", e este "novo saber" orientará para novas formas de organizar o "fazer" e compreender o "ser". Aí, sim, teríamos uma verdadeira transformação de um modelo de saúde biomédico e centrado na doença para um modelo integral e centrado na saúde e, portanto, uma mudança do paradigma positivista para o antipositivista.

Na temática "percepção do processo saúde-doença", neste caso em estudo, o PBL representa mais um limite do que uma possibilidade, visto que mais uma vez está longe de ser compatível com as necessidades de saúde das pessoas. Esta forma de ver e pensar saúde faz parte de uma visão positivista da ciência, que transmite a verdade como pronta, acabada, inquestionável. Os fatos observáveis são os únicos objetos do conhecimento da ciência, indicando a neutralidade do sujeito e do objeto, isto é, o sujeito do conhecimento não estabelece interações com o objeto do conhecimento. O positivismo consolidou-se a partir do projeto de ciência moderna centrada na busca da verdade, das leis universais que regiam o mundo, de forma a permitir a previsão dos fenômenos e o domínio da natureza, oferecendo o ideal de segurança ao homem moderno contra os infortúnios da natureza. Neste sentido, críticas são lançadas quanto ao uso da natureza, afirmando que o desenvolvimento tecnológico nos separou da natureza e que a exploração da natureza tinha sido o veículo de exploração do homem ${ }^{17}$.
O paradigma positivista tem como marcas: a racionalidade; o reducionismo (paradigma da simplificação); o mecanicismo; a dissociação entre sujeito/objeto, teoria/prática, corpo/ mente; a valorização daquilo que é quantificável como cientificamente viável, utilizando a matemática como instrumento de validação do conhecimento; crença na descoberta de leis universais generalizáveis para o funcionamento do mundo; rigor metodológico, neutralidade e objetividade do pesquisador ${ }^{17}$.

A saúde pode ser compreendida em seus múltiplos aspectos, não mais apoiada à epistemologia positivista, analítica, mas, sim, a partir de uma perspectiva de associação entre sujeito/objeto, teoria/prática, corpo/mente, em que as atividades humanas, historicamente situadas e socialmente contextualizadas, contêm valores, interesses e princípios.

\section{CONCLUSÃO}

Esta pesquisa aponta indícios e reflexões sobre uma metodologia pautada numa concepção progressista de educação, a qual se acredita capaz de promover nos alunos competências em saúde integral. Entre estes indícios e reflexões, identificamos limites e possibilidades que sugerem uma realidade onde esta metodologia favorece um modelo tradicional e promove nos alunos competências em saúde fragmentadas e biomédicas na sua formação, não contribuindo para uma formação com competências mais humanas, críticas e reflexivas.

Portanto, o método pelo método em si não garante a compreensão do processo saúde-doença em sua complexidade dialética. Mas ainda reconhecemos a possibilidade do $P B L$ enquanto prática pedagógica em prol de uma formação mais humana e crítica, desde que seja vivenciado como um método ativo de ensino nos moldes apontados na literatura.

\section{REFERÊNCIAS}

1. Backes VMS, Moyá JLM, Prado ML. Processo de construção do conhecimento pedagógico do docente universitário de enfermagem. Rev. Latino-Am. Enfermagem 2011;19(2):421-428.

2. Silva BW, Delizoicov D. Problemas e problematizações: implicações para o ensino dos profissionais da saúde. Saúde e Ambiente 2008;1(2):14-28.

3. Berbel NAN. Metodologia da Problematização: uma alternativa metodológica apropriada para o Ensino Superior. Semina, Londrina1995; 16(2):9-19.

4. Berbel NAN. Metodologia da problematização: fundamentos e aplicações. Londrina: EDUEL; 1999.

5. Berbel NAN. A metodologia da problematização com o Arco de Maguerez: uma reflexão teórico-epistemológica. Londrina: EDUEL; 2012. 
6. Cutolo LRA. Estilo de pensamento em educação médica um estudo do Currículo do curso de graduação em Medicina da UFSC. Florianópolis; 2001. Tese (Doutorado) - Universidade Federal de Santa Catarina, Centro de Ciências da Educação.

7. Gomes AP, Rego S. Transformação da Educação Médica: É Possível Formar um Novo Médico a partir de Mudanças no Método de Ensino-Aprendizagem? Rev. bras. educ. med. 2011; 35(4):557-566.

8. Gomes R, Brino RF, Aquilante AG, Avó LRS. Aprendizagem Baseada em Problemas na formação médica e o currículo tradicional de medicina: uma revisão bibliográfica. Rev. bras. educ. med. 2009; 33(3):444-451.

9. Gurpinar E, Musal B, Aksakoglu G, Ucku R. Comparison of Knowledge Scores of Medical Students in Problem-Based Learning and Traditional Curriculum on Public Health Topics. BMC Medical Education 2005; 5(7).

10. Matsu IK, Ishihara S, Suganuma , Sato Y, Tang AC, Fukui Y, Yamaguchi N, Kawakami Y, Yoshioka T.Characteristics of medical school graduates Who underwent problem-based learning. Annals Academic Medicine of Singapore 2007; 36(1):67-71.

11. Macedo RMUV. Socialização académica e desenvolvimento de identidade profissional em estudantes de fisioterapia: estudo de casos. Porto-Portugal; 2011. Tese. (Doutoramento em Ciências da Educação à Faculdade de Psicologia e de Ciências da Educação) - Universidade do Porto.

12. Bardin L. Análise de Conteúdo. Edição Revista e Actualizada. Lisboa: Edições 70; 2011.

13. Canguilhem G. O Normal e o Patológico. 6.ed. Rio de Janeiro: Forense Universitária; 2006.
14. Pellegrini Filho A, Buss PM. As iniquidades em saúde na agenda global. Le Monde Diplomatique Brasil 201; 5(52):20.

15. Brasil.Comissão Nacional dos Determinantes Sociais da Saúde - CNDSS. Determinantes Sociais da Saúde ou Por Que Alguns Grupos da População São Mais Saudáveis Que Outros? Rio de Janeiro: Fiocruz; 2006.

16. Moraes MAA, Manzini E. Concepções sobre a aprendizagem baseada em problemas: um estudo de caso na Famema. Rev. bras. educ. med. 2006; 30(3):125-135.

17. Chauí MS. Convite à filosofia. 14. ed. São Paulo, SP: Ática; 2004.

18. Callahan D. The WHO definition of health. Stud Hastings Center 1973;1(3):10.

\section{CONTRIBUIÇÃO DOS AUTORES}

Fabiola Hermes Chesani - Contribui com a coleta, resultados, análise, discussão, e parte escrita. Luiz Roberto Agea Cutolo - Contribui com a análise, discussão e conclusão. Sylvia Regina Pedrosa Maestrelli - Contribui com os resultados, análise, discussão e conclusão.

\section{CONFLITO DE INTERESSES}

Declaro que não houve conflito de interesses na concepção deste trabalho.

\section{ENDEREÇO PARA CORRESPONDÊNCIA}

Fabiola Chesani Hermes

Rua Uruguai, 458 - Bloco F6 - Sala 311

Centro - Itajaí

CEP 88302-202 SC

E-mail: fhcfisio@hotmail.com 